\title{
Entre los discursos de odio y el miedo: tirar el mal al otro lado de la frontera
}

\author{
Between hate speech and fear: throwing evil across the border
}

Anahi Sy (https://orcid.org/0000-0002-1281-5333) ${ }^{1}$

Exequiel Lopresti (https://orcid.org/0000-0003-4520-5563) ${ }^{2}$

${ }^{1}$ Instituto de Salud

\begin{abstract}
This text seeks to problematize a dominant representation about epidemics, pandemics and major catastrophes, which describes its origin as external, exotic and foreign. In general, both from Hollywood catastrophe cinema, to medical-scientific discourses, and from philosophy to conspiracy theories and hate speech, any threat or evil is placed outside of society itself, there is always another, who prosecutes a moral fault that justifies the need to combat, isolate or eliminate them. We propose to analyse arguments that have circulated around the current coronavirus pandemic, especially those that place the possibility of salvation in isolation and fear, to problematize certain ideas naturalized in discourses that are later translated into political practices or actions. Key words Coronavirus, Fear, Hate speech, Pandemic
\end{abstract}

Resumen En este texto se busca problematizar una representación dominante sobre las epidemias, pandemias y grandes catástrofes, que describe su origen como externo, exótico, extranjero y foráneo. En general, tanto desde el cine catástrofe hollywoodense, hasta los discursos médico-científicos, como desde la filosofía hasta las teorías conspirativas y los discursos de odio, se coloca cualquier amenaza o mal afuera de la propia sociedad, siempre existe un "otro", quien posee una falla moral que justifica la necesidad de combatirlos, aislarlos o eliminarlos. Proponemos analizar ciertas argumentaciones que han circulado en torno a la actual pandemia de coronavirus, especialmente aquellas que colocan la posibilidad de salvación en el aislamiento y el miedo, para problematizar ciertas ideas naturalizadas en los discursos que luego se traducen en prácticas o acciones políticas. Palabras clave Coronavirus, Miedo, Discursos de odio, Pandemia 


\section{El origen}

Las principales representaciones de epidemias y pandemias (provengan del periodismo, del discurso médico hegemónico, o de películas y libros de ficción) coinciden en exhibir una amenaza de origen externo que invade a la población y se propaga rápidamente causando muertos y terror. Aunque el peligro inmediato pueda provenir del vecino que estornuda sin tapabocas, el origen es siempre extranjero.

La actual pandemia de Coronavirus es una buena oportunidad para preguntarnos si esta representación es cierta o si esconde otra verdad más alarmante: que el origen del peligro sea interno.

Si seguimos la propagación de la pandemia actual no sobre el mapamundi, sino en sus dimensiones simbólicas, sociales e institucionales, se observa un derrotero interesante en relación a lo que muestran y ocultan los discursos sobre ella.

La enfermedad aparece en China, uno de los principales motores del sistema económico mundial. El origen sería la mutación que hace el virus de un murciélago que de pronto puede afectar a los humanos. El primer paso entonces cierra con la representación habitual: un animalito de hábitos nocturnos, asociado al menos en la cultura occidental con la oscuridad y ciertas ideas del mal. Además, este animal viene de un país que se nos representa como lejano y exótico: China. $\mathrm{Al}$ respecto aparecen múltiples prejuicios ¿Quién sabe qué extrañas y perversas prácticas pueden haber ejercido los chinos con un murciélago para causar este mal? (¿comen murciélagos los chinos por ejemplo?). Como sea, una primera frontera simbólica que se traspasa: la que separa la naturaleza y lo animal de lo humano y cultural. Ya tenemos un agente patógeno externo habitando cuerpos humanos. A partir de allí la epidemia se extiende por el mundo cuando personas infectadas viajan de un país al otro usando el muy aceitado sistema de transporte aéreo. Se cruzan fronteras y aduanas intercambiando mercancías, saludos y virus. Cuando la pandemia se declara se le pone un freno al libre intercambio de cuerpos por el mundo. Para este momento, el peligro de la Coronavirus se vuelve menos relevante a nivel individual que a nivel social: según reportan todas las fuentes el principal peligro del SARSCov-19[SARS-CoV-2?] no es su letalidad, sino su potencial riesgo de saturar sistemas de salud. El virus atraviesa otra esfera: la que va de lo individual a lo social, de los sujetos a las institu- ciones, del cuerpo individual al "cuerpo social". $\mathrm{Y}$ en paralelo, las medidas que desde el "cuerpo social" se toma para proteger a sus instituciones (el sistema de salud) y a sus integrantes -seremos los mismos sujetos quienes veremos nuestras vidas afectadas por cuarentenas y prohibiciones de circulación y reunión. Así también se ve afectada la esfera del espacio público. En todos estos saltos desde lo personal a lo social, de la naturaleza a la cultura, de lo real a lo simbólico, finalmente (o primeramente) se produce un cruce más: de la salud (enfermedad) a la economía. Las noticias de la pandemia rápidamente se propagan por el mundo de la economía, donde el libre flujo de la economía financiera y el pánico bursátil pronostican una recesión mundial que tendrá un efecto bien real en la llamada Economía Real.

En este artículo, rastreamos el recorrido de la pandemia en su traspaso del ámbito real al simbólico, lo que permite evidenciar el carácter cultural, además de natural de la enfermedad, cómo ésta afecta al cuerpo social además de individual, en qué medida se constituye en un problema económico y al mismo tiempo encuentra ahí su origen. Todo esto contribuye a evidenciar que el origen externo en el que reposan la mayor parte de las argumentaciones debe ser cuestionado.

\section{De la economía en el dominio de la naturaleza, lo que la ciencia no vió}

Lo que se sabe desde las últimas epidemias y pandemias producidas: "Vaca loca", Gripe Aviar, SARS (síndrome respiratorio agudo severo), MERS (síndrome respiratorio de Oriente Medio) Gripe A H1N1, entre muchas otras, es que el primer salto, la primera infección ocurre con la mutación de un virus que pasa de una especie animal a la humana.

Nuestra intervención en la naturaleza, que va desde el traslado de especies de un ecosistema a otro hasta la cría y reproducción en espacios artificiales, no incide únicamente en esas especies o en la calidad de los alimentos que consumimos - sean vegetales o animales - sino también en el espacio del que se extraen y en el espacio al que llegan; los mayores riesgos de producir, y no solo transmitir, sino también reproducir nuevas enfermedades reside en la forma que nos relacionamos con nuestro entorno y la forma en que producimos nuestros alimentos.

Como ha ocurrido en otras epidemias y pandemias de la historia reciente, éstas de una u otra manera fueron anticipadas por la investigación científica, si bien en ningún caso se reparó en ta- 
les investigaciones hasta que ocurrió lo que éstas predecían. Para poner un caso, respecto de la llamada Gripe AH1N1, la revista Science en el año 2003 había publicado un artículo sobre la mutación del virus de la gripe porcina y su relación con la forma de producción animal -concentrar un enorme número de animales en espacios muy reducidos ${ }^{1}$; en enero de 2009, un artículo publicado en Science advierte que el virus A (H1N1) pasó de los cerdos a los humanos, entre noviembre de 2008 y enero de 2009, y pudo haber comenzado a infectar a gran cantidad de personas a partir de marzo ${ }^{2}$. Para el caso del coronavirus, ya se había publicado en el año 2016 en Proceedings of the National Academy of Sciences of the United States of America, un trabajo que que señalaba la probabilidad de la ocurrencia de futuros brotes de coronavirus similares al SARS-CoV ya conocido, originado en murciélagos ${ }^{3}$. A cuatro años de contar con dicha información, comenzaron los primeros casos con una propagación tan acelerada que hacía imposible prever las dimensiones y las consecuencias de algo que había sido pronosticado.

Lo que no prononticaba ni vió la ciencia disciplinar/disciplinada es que así como los virus mutan y contagian a las personas, también en su dispersión llegan a afectar al cuerpo social y a la economía.

En otras palabras, el mal que amenaza con matar a miles de personas, aislar a millones, colapsar sistemas de salud y arrasar los etéreos mercados, no proviene de un agente totalmente externo y exótico sino que es originado por la propia forma de producción de alimentos de la economía globalizada.

Aunque esto también abre nuevos mercados, no solo el de medicamentos sino también de bioseguridad y de la seguridad en general. Todo es capitalizable, desde las necesidades más básicas como el hambre o la salud hasta las probabilidades de contagio o de terrorismo biológico (en el que se sustentan las teorías conspirativas sobre el origen de los virus pandémicos). Las explicaciones conspirativas que vuelven a colocar el mal afuera, en "el otro", han tenido lugar con cada nueva epidemia, en países de orientaciones políticas muy disimiles e incluso opuestas se repiten los relatos que remiten al bioterrorismo que busca atacar y controlar el espacio social. Todo ello no hace más que ocultar el origen interno que la engendra.

\section{De los "discursos del miedo" a los "discursos de odio"}

Desde la modernidad hemos naturalizado la idea de que el miedo es algo subjetivo y exterior a la política. Sin embargo, la investigación antropológica desde sus inicios advierte que, si bien las emociones son fenómenos psíquicos que involucran la dimensión del cuerpo, se trata de pensamientos corporeizados ${ }^{4}$, como ya había advertido Marcel Mauss ${ }^{5}$, se trata de hechos sociales, pues sus manifestaciones están pautadas culturalmente: aprendemos cómo sentir. Al mismo tiempo, las emociones son hechos semióticos significativos, comunicativos, dotados de sentido y de sentimiento. En cada sociedad se aprende cómo sentir - por ejemplo a qué temer, de qué forma hacerlo y cómo reaccionar ante la amenaza que atemoriza. Las experiencias de aprendizaje en el ámbito familiar y de diversas instituciones sociales así como las producciones culturales, van a contribuir a la producción y reproducción de modos de sentir que van a modelizar la producción de subjetividad, identificaciones y diferencias, miedos y odios.

En este artículo, cuando hablamos de miedo, no referimos a lo personal, sino al miedo político, se trata aquel que genera algún tipo de ansiedad sobre un peligro que se proyecta pueda afectar el bienestar colectivo - inseguridad, decadencia moral, el colapso de los sistemas de salud y de la economía. El miedo personal es el temor a enfermarse uno, que queda sólo en la persona que lo padece. El miedo político es el temor proyectado desde y hacia lo colectivo, a la relación con otros.

El miedo es contagioso y aísla, como el Coronavirus. $\mathrm{Y}$ sin embargo, una narrativa que se está estableciendo para interpretar a la actual pandemia, sostiene que el miedo y el aislamiento en la crisis tienen un lado positivo. Nos da a cada uno la oportunidad de tomar consciencia de los males del modelo actual de capitalismo globalizado, lo que abriría la posibilidad de salir de esto hacia otro modelo de sociedad más justo, post-materialista o consumista. Podemos encontrar este argumento de optimismo progresista en todos lados: desde los mensajes en redes-sociales alegrándose por el regreso de aguas transparentes de Venecia, pasando por programas periodísticos bien intencionados, hasta intelectuales como Berardi o Zizek.

Reconozcamos quienes sostienen ese argumento tienen el corazón en el lugar correcto. El 
auténtico peligro es el relato conservador, que sostienen figuras políticas como Trump o Bolsonaro, cuyos discursos de odio buscan, al mismo tiempo, negar la crisis y sostener la actividad económica como si nada pasara. Como toda película del cine catástrofe hollywoodense ubica el origen del mal fuera de la comunidad. Comienza con un murciélago, un oscuro animalito nocturno, y un oriental que se lo come en un festín exótico -como siempre, orientales y traidores son, sino sinónimos, palabras afines. Se representa a los otros con una falla moral que justifica la necesidad de combatirlos, aislarlos o eliminarlos. Socialmente se pasa del virus en la propia sociedad a la idea del virus colocado en el otro, diferente, enemigo, exótico.

Los discursos más progresistas fundan su optimismo en la responsabilidad social, que funcionó bien mientras el miedo tenía un espacio protagónico y el rol del estado pasaba por gobernar el miedo, sin embargo, en gobiernos como el argentino, que podríamos llamar exitosos en términos de las medidas tempranas que se tomaron para el control de la pandemia, la tranquilidad, seguridad y control de la situación que se logra instalar en la sociedad (sumado a necesidades impostergables de muchos), conducen a una situación donde el miedo cede y da lugar a conductas individualistas, cuando de la sociedad y el bien común se pasa a pensar en el bienestar y libertad individuales. Ante esto muchos plantean la necesidad de volver a estos "discursos del miedo".

El miedo es visto con el potencial de regular las conductas de todo el mundo (todos en cuarentena o enfermos) y hacerlos reflexionar sobre sus propias faltas morales: haber sido egoístas o consumistas, por ejemplo. Y a partir de eso lograr el arrepentimiento y la redención. En esta "solución" el miedo actúa como una fuerza capaz de galvanizar a una sociedad idiotizada por los medios de comunicación, embobada por el consumismo, perdida en lógicas narcisistas. El miedo funciona aquí como un despertador, como una electricidad que sacude al cuerpo social ${ }^{6}$. Y el aislamiento siguiente permite un proceso de introspección y reflexión bajo la luz de ese miedo.

Es importante notar que para que esta operación tenga lugar el miedo tiene que ser entendido como un elemento externo y anterior a la sociedad y a la cultura. En otras palabras: el miedo es entendido como un instinto, no como una construcción cultural. Si el miedo es interpretado como algo intrínseco a la sociedad y producido por la misma cultura, aprendido e interiorizado por el sujeto a través de varias instituciones so- ciales, entonces puede verse que no tiene esa capacidad de re-generar la situación de decadencia sociocultural en la que nos encontraríamos.

Lo que se busca entonces es retrotraernos a un momento anterior y distinto al estado de cosas actual en el que el problema no existía. Aquí se ve que es un argumento típicamente conservador: no fuga hacia adelante sino hacia atrás. Busca conservar el statu-quo social en lugar de transformarlo. El objeto puede ser el miedo al virus u otro. No importa. Siempre es un elemento que permite culpar a alguien, castigarlo, obligarlo a arrepentirse, eliminar el pecado que ese alguien o ese grupo introdujo en lo social.

El segundo elemento de este relato supone que el miedo y el encierro nos harán reflexionar sobre los excesos del capitalismo, de tal modo que surgirá una mayoría de ciudadanos comprometidos y críticos que podrá pujar por una economía sustentable y una sociedad más justa. No es que esta opción esté clausurada. Es deseable para una posición de izquierda y hay que abogar por ello. Pero aún si ignoramos que la dinámica de las redes sociales tiende a fijarnos en nuestros prejuicios antes que obligarnos a pensar más allá de ellos. Aún si aceptamos la dudosa premisa de que todos y todas seamos capaces de convertirnos en Descartes cuarentenados para buscar la verdad armados de nuestra razón como espada y la introspección como escudo. Aún así la pregunta que deberíamos hacernos es la siguiente ¿Desde cuándo es una propuesta de izquierda que la introspección individual sea un camino hacia la mejora de la sociedad? Razonar de este modo nos aproxima más al género de la autoayuda que a un debate social abierto y democrático que discuta qué sociedad queremos. Para decirlo de otro modo: hay muy poco pueblo en la calle durante una cuarentena.

Los discursos de odio más conservadores, en algún punto convergen con los anteriores cuando promueven no solo el odio racial, de clase, etc., sino también el temor y el miedo de la diferencia, lo diferente u otro extraño/extranjero/exótico. Ese miedo opera de la misma forma, todas son construcciones socioculturales.

\section{El fin de la pandemia}

Si todo esto va a tener un final que no sea una catástrofe social, será en el momento en que podamos recuperar el espacio público, no mientras estemos escondidos debajo de la cama rumiando nuestras peores pesadillas. Una salida por izquierda de la cuarentena, de la pandemia 
y del miedo, si es que va a haberla, pasará por dejar de ver al miedo como un agente externo, que vigorice lo social, y volver a entenderlo como una construcción sociocultural. Ese primer paso permitirá volver a enfocarnos en el problema que ya tenemos bien definido: que el causante de la pandemia no fueron los exóticos hábitos alimentarios de algún gourmet asiático, sino el resultado de procesos de producción dentro del capitalismo actual. $\mathrm{Y}$ armados de ese conocimiento podemos debatir y organizarnos, para desarmar el entramado económico que nos metió en esto, sin necesidad de apelar a regeneradores morales.

Convencidos de carecer de principios que sostengan la vida pública, siempre está al acecho la posibilidad de validar la experiencia del miedo. Al considerar el miedo como pilar de la vida en común, nos rehusamos a reconocer que éstos, nuestros temores, no son más que los síntomas manifiestos de los conflictos permanentes en sociedades injustas y desiguales. Siendo incapaces de evidenciar los conflictos reales que hacen del miedo un instrumento político, se hace imposible la búsqueda de herramientas para enfrentar dichos conflictos; todo lo cual, en último término, redunda en que sigamos siendo sometidos y dominados por el miedo. Si se entendiera los objetos de nuestros miedos y odios como verdaderamente políticos, se discutiría sobre ellos como se hace sobre otras cuestiones que se reconoce como problemas políticos; sin embargo no es ese el lugar que ocupa el miedo o el odio en la arena política.

Los médicos saben poco del COVID-19 y quienes no lo somos todavía menos. Está claro que es muy contagioso, al igual que el miedo. También está claro que no les hace crecer ni un corazón ni un cerebro a quienes no los tenían antes. El miedo y el encierro tampoco tienen ese efecto regenerativo.

Hay que comenzar por entender eso para poder empezar a pensar cómo salir hacia adelante, no hacia atrás. No hay que confundir utopía con arcadia.

\section{Colaboradores}

La primera autora, A Sy, tuvo la idea original de escribir sobre el tema, desarrollo parte de la argumentación junto al co-autor, E Lopresti, quien es experto en análisis culturales, desarrollo gran parte de los argumentos expuestos en el trabajo. 


\section{Referencias}

1. Wuethrich B. Infectious disease: chasing the fickle swine flu. Science 2003; 299(5612):1502-1505.

2. Fraser C, Donnelly CA, Cauchemez S, Hanage WP, Van Kerkhove MD, Hollingsworth TD, Griffin J, Baggaley RF, Jenkins HE, Lyons EJ, Jombart T, Hinsley WR, Grassly NC, Balloux F, Ghani AC, Ferguson NM, Rambaut A, Pybus OG, Lopez-Gatell H, Alpuche-Aranda CM, Chapela IB, Zavala EP, Guevara DM, Checchi F, Garcia E, Hugonnet S, Roth C; WHO Rapid Pandemic Assessment Collaboration. Pandemic potential of a strain of influenza A (H1N1): early findings. Science 2009; 324(5934):1557-1561.

3. Racaniello V. Moving beyond metagenomics to find the next pandemic virus. PNAS 2016; 113(11):28122814.

4. Rosaldo M. Toward an Anthropology of self and feeling. In: Shweder RA, Levine RA, editors. Culture theory: essays on minf, self and emotions. Cambridge: Cambridge University Press; 1984. p. 127-157.

5. Mauss M. Sociología y antropología. Madrid: Editorial Tecnos; 1979.

6. Corey R. El miedo. Historia de una idea política. México: Fondo de Cultura Económica; 2009.

Artículo presentado en 18/09/2020

Aprobado en 18/12/2020

Versión final presentada en 20/12/2020

Editores jefes: Romeu Gomes, Antônio Augusto Moura da Silva 